\section{Galileo takes interesting but indirect route to Jupiter}

Washington

GALILEO, the most sophisticated planetary probe ever built, is currently sitting in pieces at the Jet Propulsion Laboratory (JPL) in Pasadena, California. But all that will change shortly. Mission scientists have determined the precise date it should arrive at Jupiter, and mission engineers will next month reassemble the craft, in preparation for its October 1989 launch.

Once, Galileo was a one-planet mission, but necessity has forced more elaborate plans. Cancellation of two different booster rockets has meant that there is no launch system at present in the US fleet that can place Galileo onto a direct trajectory for Jupiter. So last year, JPL scientists came up with a planetary tour dubbed VEEGA (for Venus, Earth, Earth-gravity assist) that will get Galileo to Jupiter in 6 years. The space shuttle Discovery will boost Galileo into Earth orbit, and an IUS (inertial upper stage) will start the craft on its planetary tour.

After launch, the spacecraft will fly towards the Sun, receiving a gravity boost from Venus in February 1990. Galileo will then return to Earth in December 1990 for a second gravity assist, going into a twoyear solar orbit that will bring the spacecraft within $1,000 \mathrm{~km}$ of Gaspara, a type $\mathrm{S}$ asteroid $15 \mathrm{~km}$ in diameter. Arriving back at Earth in December 1992, Galileo will receive a third gravity assist to begin its journey to Jupiter.

Outward bound to Jupiter, Galileo will encounter Ida, another type S asteroid in August 1993. Five months before arriving at Jupiter, Galileo's planetary probe will be released (Galileo is really two spacecraft in one). The probe will follow a ballistic trajectory into Jupiter's atmosphere at $6^{\circ} \mathrm{N}$ latitude. The Galileo orbiter will make a minor adjustment to its trajectory so it will orbit the planet, receiving yet another gravity assist from Io as it approaches the planet. The orbiter will orbit overhead for five minutes as the probe sends back data on its descent to the planet's surface.

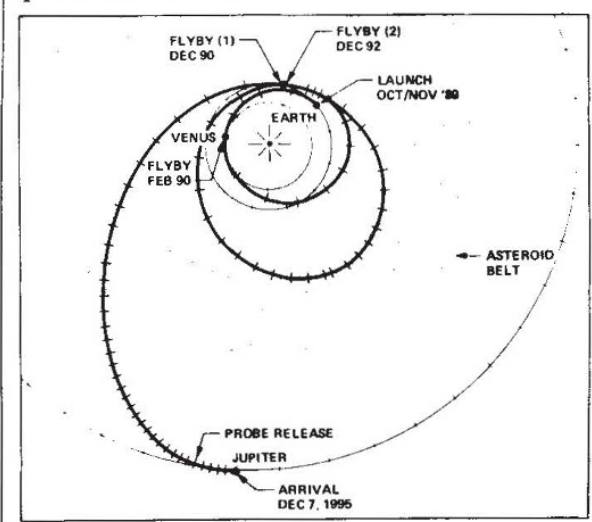

Trajectory for the Galileo spacecraft. Subdivisions marked on each orbit represent 100 days for Jupiter, and 30 days for the spacecraft, Earth and Venus.

Galileo scientists intend to take advantage of its complicated trajectory. At Venus, for example, Galileo's infrared spectrometer will be used for studies of the atmospheric composition. During the Earth-Moon encounters, Galileo will be able to make near-infrared measurements of the far side of the Moon for the first time.

The change in trajectory has forced extensive modifications to the spacecraft, such as sunshades designed for sensitive instruments.

\section{Another AIDS vaccine}

A SECOND vaccine against AIDS has been given clearance by the US Food and Drug Administration for testing in humans. The vaccine, developed by the Oncogen subsidiary of Bristol-Myers, consists of vaccinia virus containing the genes for the coat proteins for HIV-1.

The vaccine will be administered to between 30 and 60 HIV-negative homosexual volunteers, at the Pacific Medical Center in Seattle, Washington, to determine its safety and immunogenicity.

The first AIDS vaccine in the United States, developed by MicroGeneSys and the US National Institutes of Health, was approved for testing in humans in August. It is based on the coat protein gp 160 .

The efficacy of any vaccine is not determined until Phase III clinical trails. The vaccine developed by Oncogen has shown encouraging results in chimpanzees, however (Nature 328, 721-723; 1987). C.E.

\section{Biogen patent}

THE troubled biotechnology company Biogen has received a US patent for hepatitis-B antigens produced through genetic engineering that could be a significant source of revenue to the company, whose financial statements have been running deeply in the red. Biogen will not develop hepatitis-B products, but royalties from licensing the patent to producers of hepatitis-B vaccines and tests could earn them up to 10 per cent of the estimated $\$ 200$ million market for the products. C.E.

\section{New NIMR director}

DR John Skehel (rhymes with flail) has been appointed director of the National Institute of Medical Research, Mill Hill the largest of the UK Medical Research Council's laboratories. A 46-year-old virologist, Skehel has worked at the institute since 1969 and has been head of one of its four divisions for the past two years. He takes over a post once held by Sir Peter Medawar from Dr Dai Rees, new secretary of the Medical Research Council. Skehel's research has concentrated on influenza viruses, particularly on the haemagglutinin protein. Recently, his attention has turned to the envelope protein of the human immunodeficiency virus.

P.N.

\section{MRC cold unit closes}

BrITAIN's Medical Research Council is to close its 40-year-old Common Cold Unit in Wiltshire when the unit's director, Dr David Tyrrell, retires in 1990. More than 18,000 volunteers have passed through the unit, whose annual budget is $£ 500,000$.

S.L.H. 